\title{
Recorregut geològic i mineralògic per les comarques de Matarranya i dels Ports: des de Fontdespatla a Pena-Roja de Tastavins i a Herbers i Bolinxa
}

Josep Maria Mata-Perelló

Andrés Pocoví Juan

Joaquim Sanz Balagué

Jaume Vilaltella

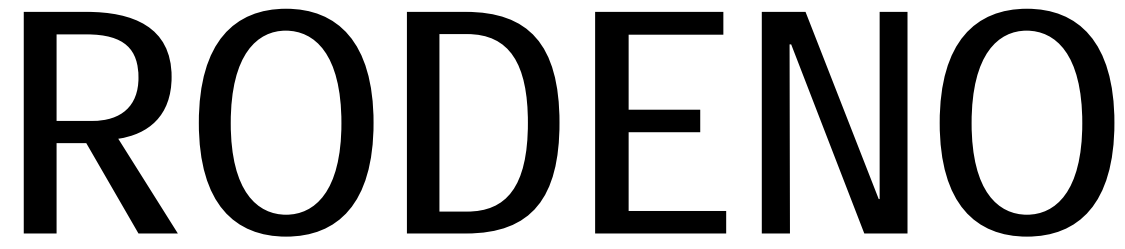

\section{REVISTA DE GEOLOGÍA ARAGONESA}

\section{n. 3}

SEPTIEMBRE 2015 


\title{
RECORREGUT GEOLÒGIC I MINERALÒGIC PER LES COMARQUES DE MATARRANYA I DELS PORTS: DES DE FONTDESPATLA A PENA-ROJA DE TASTAVINS I A HERBERS I BOLINXA
}

\author{
Josep Maria Mata-Perelló \\ Museu de geologia Valentí Masachs, Escola Politècnica Superior d'Enginyeria de Manresa \\ (EPSEM), Universitat Politècnica de Catalunya · BarcelonaTech (UPC), 08272 Manresa, Spain
}

\author{
Andrés Pocovi Juan \\ Universidad de Zaragoza, Departamento de Ciencias de la Tierra ( DCT- UZ) \\ Joaquim Sanz Balagué \\ Departament d'Enginyeria Minera i Recursos Naturals (EMRN), Escola Politècnica Superior \\ d'Enginyeria de Manresa (EPSEM), Universitat Politècnica de Catalunya - BarcelonaTech \\ (UPC), 08272 Manresa, Spain
}

Jaume Vilaltella Farràs.

Sociedad Española para la Defensa del Patrimonio Geológico y Minero (SEDPGYM)

Palabras clave: patrimonio minero; patrimonio geológico

\section{Resum}

Recorregut realitzat el 17 de novembre de 2013. També en aquesta ocasió, el recorregut del present itinerari discorrerà per una zona en la qual conflueixen tres unitats geològiques netament diferenciades: la Depressió Geològica de I'Ebre, la Serralada Prelitoral Catalana (del Sistema Mediterrani), i la Serralada Ibèrica.

Així, en el primer tram del recorregut, entre Fontdespatla i Pena-roja de Tastavins aquest oscil-larà entre les dues primeres unitats geològiques, efectuant-se parades tant en una com a l'altra. Després, entre Pena-roja de Tastavins i la fi del recorregut (molt prop del Port de Torre Miró, el recorregut recalarà a les dues últimes unitats geològiques esmentades, però especialment la Serralada Ibèrica.

Per d'altra banda, el recorregut de l'itinerari, es realitzarà per dues comarques: una d'elles de la Regió de Tortosa, concretament per la comarca aragonesa del Matarranya; i l'altra de la Regió de Castelló: la comarca dels Ports. El recorregut començarà a la primera, per finalitzar a la segona. 


\section{ADVERTIMENTS PREVIS}

Com en altres recorreguts de RECERCA GEOLÒGICA I MINERALÒGICA ..., si es disposa del temps suficient, poden efectuar-se passant per totes les parades i filloles. En cas contrari, recomanem prescindir de les anomenades PARADES - CONDICIONALS.

També recomanem de cercar la informació més adient, sobre els trams a recórrer mitjançant camins de terra, o de pista. Precisament, en aquest itinerari, hi ha alguns trajectes d'aproximació cap a les mines, que haurem de fer per camins de terra en irregular estat de conservació.

Per d'altra banda, recomanem tenir una cura extrema de la NATURA, evitant qualsevol forma d'agressió sobre ella, o de fer-n'hi un mal ús del que en ofereix la nostra mare Terra.

\section{OBJECTIUS FONAMENTALS D’AQUEST ITINERARI}

Els objectius fonamentals que es pretenen aconseguir en aquest itinerari, es poden concretar en els següents aspectes generals:

1.- Observació i descripció dels materials terciaris (de l’Eocè i de l'Oligocè) de la Depressió Geològica de l'Ebre, que pertanyen majoritàriament al Grup Guadalope Castellote. Aquests materials, els anirem trobant a diferents indrets del primer tram del recorregut, especialment entre Fontdespatla i Pena-roja de Tastavins. Cal dir bona part d'aquesta zona, s'inclou dintre del denominat Avant-país, situat al contacte entre la Depressió Geològica de l’Ebre i la Serralada Ibèrica.

2.- Observació i descripció dels materials mesozoics (del Triàsic, del Jurassic i del Cretàcic), que constitueixen la Serralada Prelitoral i el Sistema Ibèric, a la seva Zona $d^{\prime}$ Enllaç. Aquests materials els trobarem a diferents indrets del recorregut de l'itinerari, especialment entre Pena-roja de Tastavins i el final del recorregut.

3.- Observació de les estructures locals d'aquests materials, al llarg del recorregut de l'itinerari, i de les relacions existents entre les tres unitats geològiques acabades d'esmentar, i en especial: visió de les estructures de la Zona d'Enllàç.

4.- Observació i reconeixement de diferents mineralitzacions situades a diferents indrets del recorregut de l'itinerari, (però sempre dintre de la Zona d'Enllaç), com les formacions $i$ antigues explotacions bauxitiferes de Fondespatla, que trobarem reblin cavitats d'origen kàrstic entre les calcàries mesozoiques del Juràssic.

5.- Observació de les antigues explotacions mineres relacionades amb les mineralitzacions anteriors. Al respecte, cal dir que totes elles es troben actualment aturades. 
6.- Observació de les empremtes de la darrera riada del riu Tastavins, prop de la població de Pena-roja.

7.- Observació de les formacions kàrstiques dels voltants d’Herbers, amb diferents dolines i poljès.

8.- Observació i anàlisi dels impactes produïts sobre el Medi Natural (i sobre el Medi Ambient), tant per les explotacions mineres anteriors, com per altres activitats humanes.

9.- Observació dels diferents indrets relacionats amb el Patrimoni Geològic i Miner, que trobarem al llarg del recorregut.

\section{ANTECEDENTS BIBLIOGRÀFICS}

Pel que fa al recorregut del present itinerari, existeixen diferents antecedents bibliogràfics molt propers, obra d'un dels autors del present itinerari. Es tracta de MATAPERELLÓ (1996a, 1996b, 1997, 1989, 2000, 2006a i 2006b); i també de MATAPERELLÓ i MONTANÉ GARCÍA (2003).

Pel que fa a la descripció de les mineralitzacions, cal fer esment d'altres treballs del mateix autor: MATA-PERELLÓ (1991), relatiu al conjunt de les mineralitzacions catalanes en general; i MATA-PERELLÓ (1992), relatius a l'inventari mineralògic de la comarca del Matarranya.

I, finalment, pel que fa a l'estructura geològica de la zona per la qual discorre l'itinerari, farem esment dels treballs de: GUIMERÀ et altri (1982) i de RIBA et altri (1976). També, i dintre d'aquest apartat, també farem esment de diversos treballs de l'IGME (1972 i 1976). Tots ells són relatius a diversos fulls geològics corresponents als indrets per on passarà el recorregut de l'itinerari.

Tots aquests treballs referenciats, i d'altres, figuren esmentats per ordre alfabètic a l'apartat dedicat a la BIBLIOGRAFIA.

\section{RECORREGUT DE L'ITINERARI}

El recorregut de l'itinerari començarà dintre de la comarca del Matarranya, a la població, de Fondespatla, des d'on es dirigirà cap a Pena-roja de Tastavins. En aquest tram s'efectuaran diverses aturades, sempre dintre de la comarca del Matarranya. 
Després, el recorregut es dirigirà cap a Herbers, penetrant a la comarca dels Ports, per tal d'anar finalment cap a Bolinxa, prop d'Herbeset. En aquest tram es faran diverses aturades més.

\section{DESCRIPCIÓ DE L'ITINERARI}

Com de costum, estructurarem el recorregut de l'itinerari en una sèrie de PARADES, que tot seguit anirem veient. En cadascuna d'aquestes aturades farem un breu comentari (geològic o mineralògic, segons s’escaigui).

Cada una d'aquestes parades tindrà un número, i un topònim representatiu. Per d'altra banda, s'indicarà el nom del poble més proper, el municipi al qual pertany l'indret, i la comarca on es troba situat. Per d'altra banda, també indicarem en cada cas, i entre parèntesi, el full topogràfic on es troba l'aturada.

Finalment, cal dir que el recorregut de l'itinerari s'inclourà dintre dels següents fulls, del "Mapa Topográfico Nacional", realitzats a l'escala 1:50.000 per l'"Instituto Geográfico y Catastral": 520 (dit de Pena-roja de Tastavins) i 521 (anomenat de Beseit.).

Així doncs, la relació de parades ordenades, que composen aquest itinerari geològic i mineralògic, és el següent:

PARADA 1. ERMITA DE SANT MIQUEL, (terme de Fondespatla, comarca del Matarranya). (full 520).

El recorregut de l'itinerari el començarem per les immediacions del poble de Fondespatla. Per arribar-hi, ens caldrà creuar el poble, per tal d'agafar el camí que va cap a l'ermita de Sant Miquel. Ens caldrà arribar fins un replà situat abans d'un petit pont. Aquí, a uns $1 \mathrm{Km}$ del poble, farem la primera aturada.

Tot aquest recorregut, des de que hem retornat a la carretera, fins a l'indret de l'aturada, s'haurà fet entre els materials oligocènics del Grup Guadalope - Castellote, que són els que apareixen a l'indret de l'aturada, ja que ens haurem estat desplaçant per la Depressió Geològica de l'Ebre, on ens trobem ara situats.

Aquí podem observar una inflexió amb la vergència de les estructures de la Zona d'Enllaç, es passa d'una direcció ENE-OSO, a una altra ESE-ONO és a dir; de direccions de tipus català a altres d'ibèrics.

PARADA 2. PONT SOBRE EL RIU TASTAVINS, (terme municipal de Penya-roja de Tastavins, comarca del Matarranya). (Full 520). 
Des de la parada anterior, cal anar cap a Pena-roja de Tastavins / Peñarroya de Tastavins. En arribar-hi, caldrà superar el poble, per tal de parar a les immediacions del pont sobre el riu Tastavins, a la carretera que condueix cap a Herbers. Així, haurem efectuat un recorregut proper als 7'5 Km, des de la parada anterior.

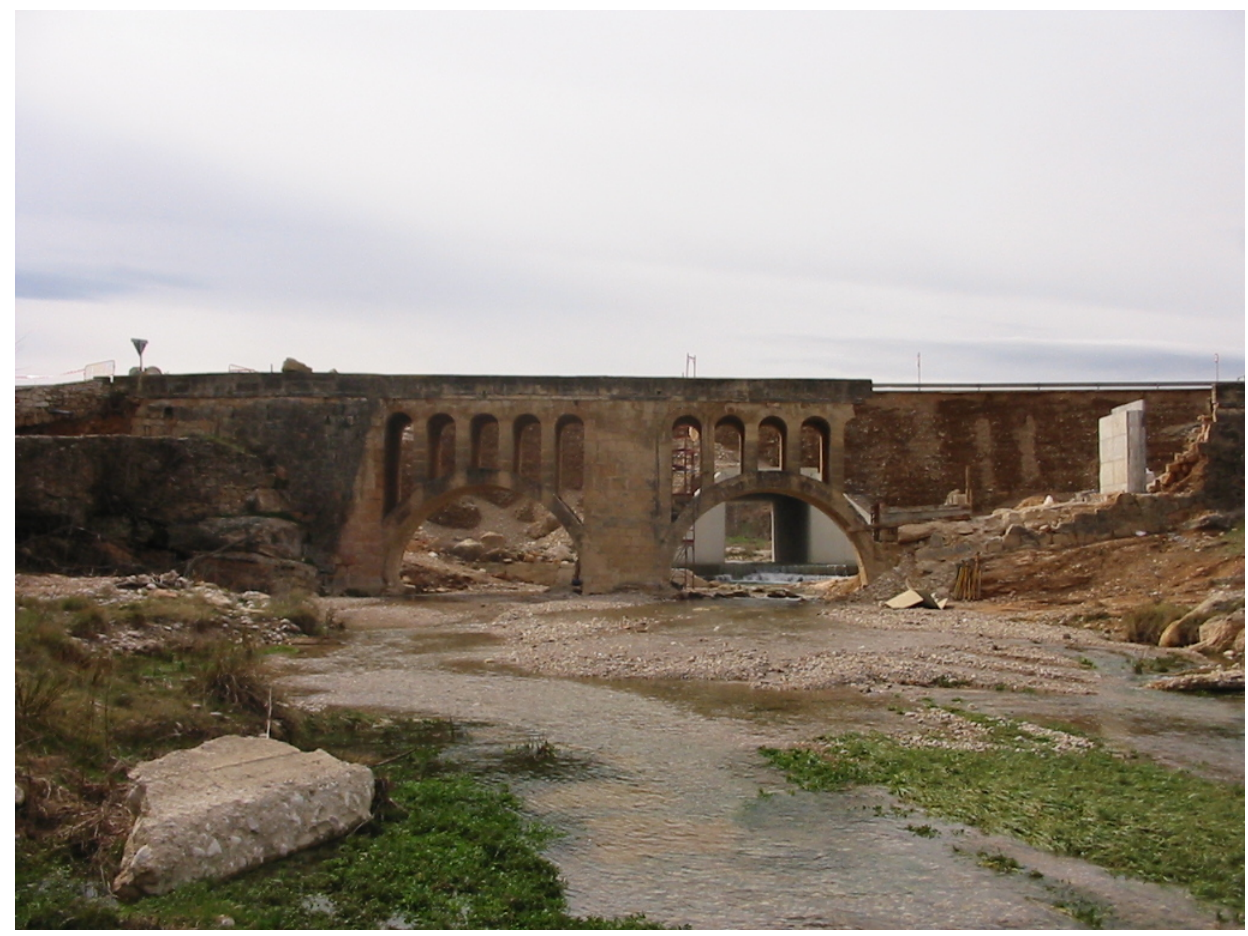

FOTOGRAFIA 1. PARADA 2

En primer terme el Pont Medieval (amb tres “ulls”)

i al darrera el pon nou (amb un sol "ull”) 


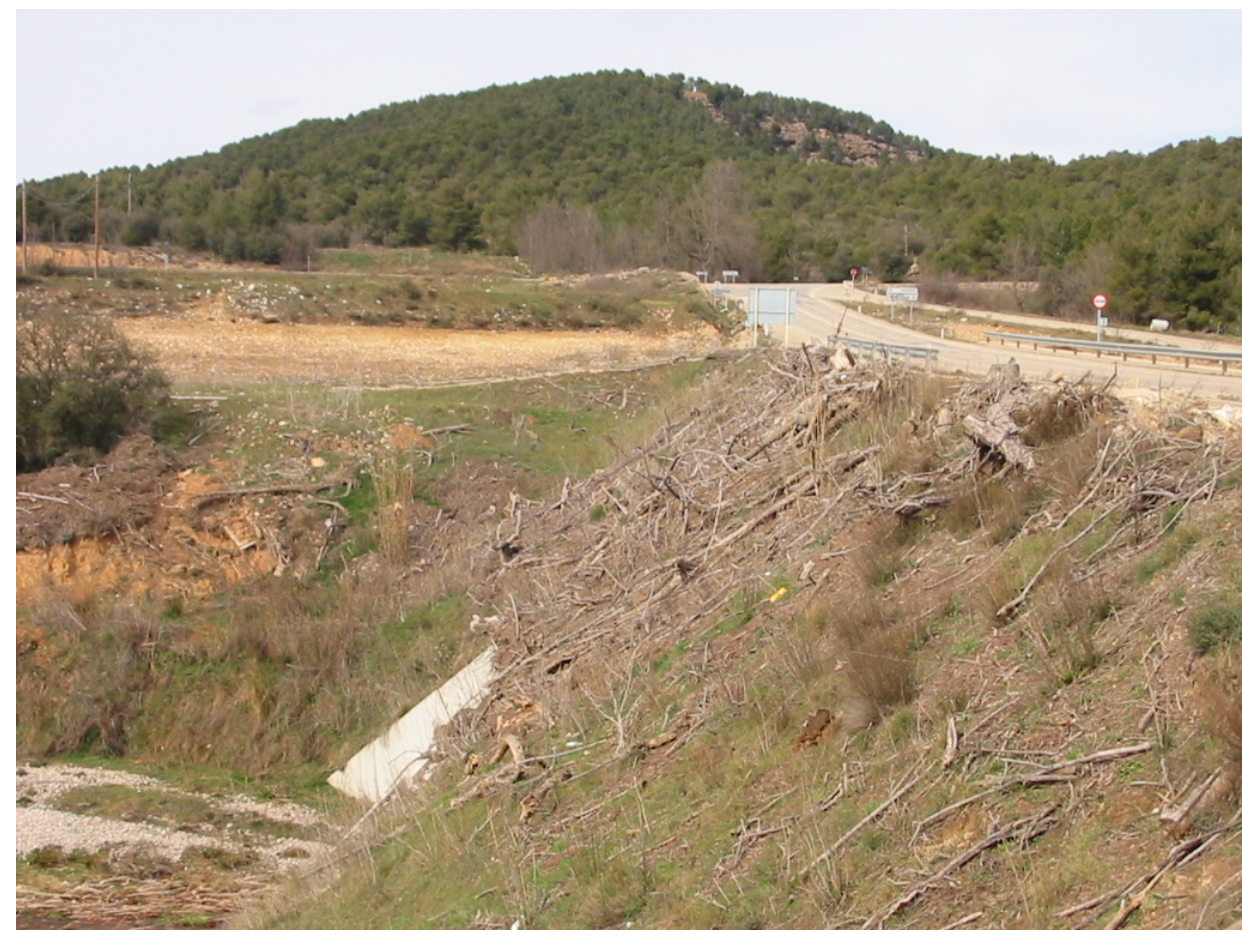

FOTOGRAFIA 2. PARADA 2

La brossa acumulada darrera del pont nou

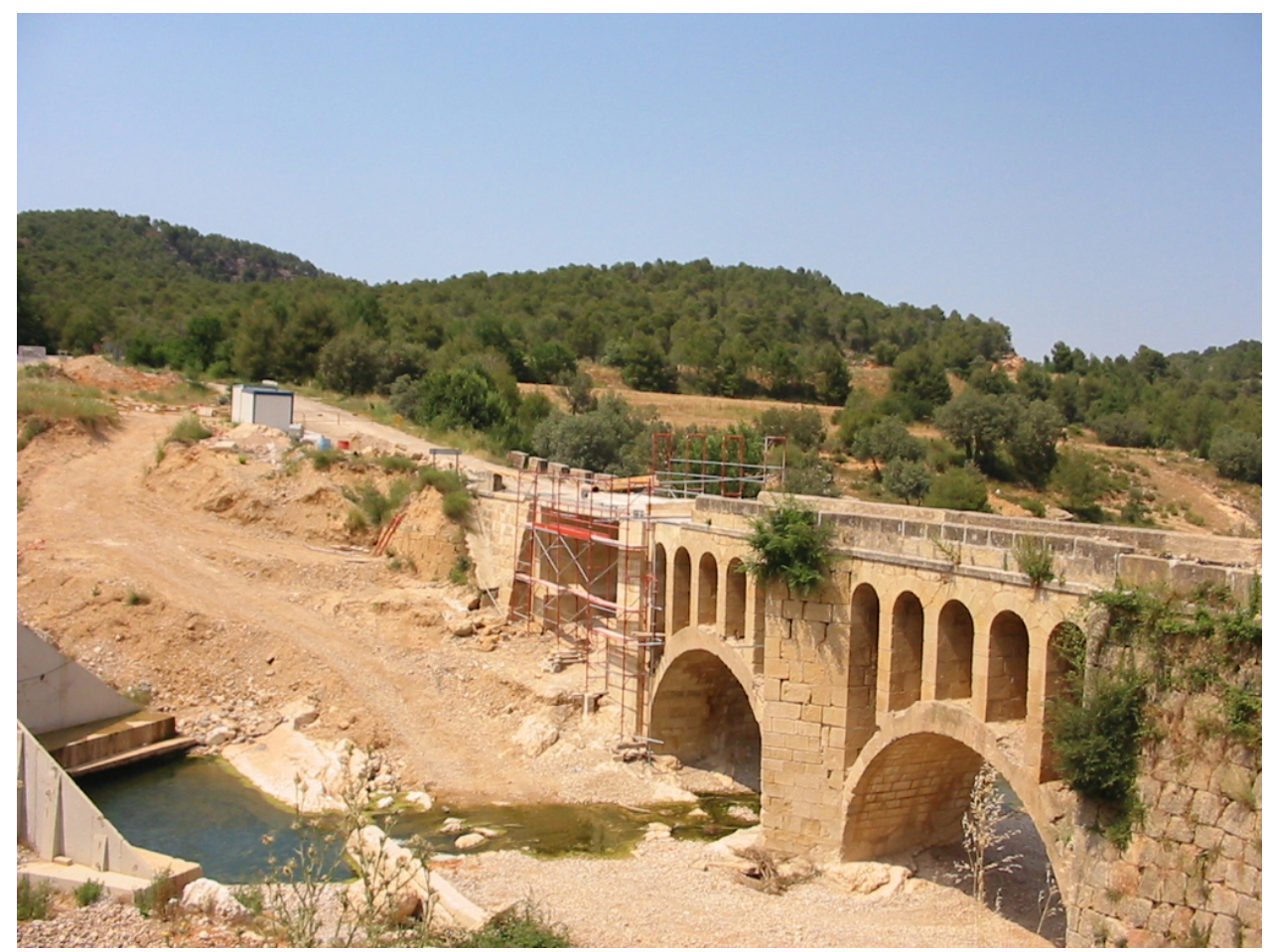

FOTOGRAFIA 3. PARADA 2

Un altre aspecte del pont nou 
Tot aquest recorregut, l'haurem efectuat entre els afloraments dels materials oligocènics, de caràcter eminentment detrític, els quals pertanyen a Complex de Mont-roig, Aiguaviva i Alcorisa. Tots aquests materials pertanyen a la Zona de l'Avant-país, de la Depressió Geològica de l'Ebre.

En aquest l'indret on efectuem la present parada, i mirant cap al Sud, es pot veure l'encavalcament dels materials mesozoics del Sistema Ibèric, sobre els materials terciaris que afloren pels indrets on ara som.

En aquest indret, es poden veure els desastres ocasionats per la darrera riada del riu Tastavins,. Aquesta riada va destrossar el pont medieval, que estava situat aigües avall d'un pont actual mal dissenyat, amb un "ull” molt petit. Tota la brossa de la riada, el va obturar, ien sortir l'aigua a pressió va trencar el pont vell, de tres "ulls". Cal dir, que aquesta situació de risc, va a estar a punt de trinxar el proper Monestir. FOTOGRAFIES 1, 2 i 3.

\section{PARADA 3. VOLTANTS DELS MAS DE CAPOLLETA, BARRANC D'ESCRESOLA, (terme municipal de Penya-roja de Tastavins, comarca del Matarranya). (full 520)}

Des de la parada anterior, cal continuar cap a Herbers. Tot i així, en arribar a les immediacions del Mas de Capolleta, front al barranc d'Escresola, caldrà fer la present aturada, després de recórrer uns $2 \mathrm{Km}$, des de la parada anterior.

En aquest recorregut, haurem trobat inicialment els materials terciaris esmentats a la parada anterior, els del Complex de Mont-roig, Aiguaviva i Alcorisa. També haurem trobat afloraments més lutítics, els quals pertanyen al Grup del Matarranya-Castellote.

Tot i així, una mica més amunt del Mas de Capolleta, haurem trobat l'encavalcament dels materials mesozoics del Sistema Ibèric (els quals es troben més al Sud d'on ara som) per sobre dels materials terciaris anteriors.

\section{PARADA 4. VOLTANTS DELS MAS DEL SOBIRÀ, (terme municipal de Pena-roja de tastavins, comarca del Matarranya). (full 520).}

Després de fer l'aturada anterior, cal fer un breu recorregut de menys de $1 \mathrm{Km}$, per tal d'arribar a l'indret de la nova aturada. Aquest lloc es troba situat a la vora de la carretera.

En aquest recorregut hem trobat els materials esmentats a la parada anterior. Tot i així, en aquest indret podem observar com els materials mesozoics es troben intensament replegats. Aquest plegament és en gran part aparent. Ens trobem en el front mateix d'un encavalcament i els materials que tenim enfront estan verticals. Considerant 
aquesta posició geomètrica de les capes i el fet de que estan parcialment erosionades podrem extreure conclusions sobre les deformacions de detall d'aquest aflorament.

\section{PARADA 5. IMMEDIACIONS DEL MOLÍ DEL BARÓ, CARRETERA A HERBERS, (termes municipals de Penya-roja de Tastavins i d'Herbers, comarques del Matarranya i dels Ports). (Full 520).}

Des de la parada anterior, cal continuar cap al proper poble d'Herbers. Poc abans d'arribar-hi, a menys de $1 \mathrm{Km}$, per les immediacions del Molí del Baró, caldrà fer la present aturada, després de fer un recorregut de prop de $2 ` 5 \mathrm{Km}$, des de la parada anterior.

En aquest recorregut, des de la parada anterior, hem continuat trobant els materials mesozoics esmentats anteriorment (del Juràssic i del Cretaci), els quals formen part de la Serralada Ibèrica, tot i que són encara molt propers a la denominada Zona d'Enllaç, de la qual ja n’hem parlat a les parades anteriors.

Per d'altra banda, en aquest recorregut, a menys de $1 \mathrm{Km}$, abans d'arribar a Herbers, es pot veure un sinclinal, tot mirant cap a l'esquerra del riu:

\section{PARADA 6. SORTIDA DEL POBLE D'HERBERS - CAMÍ DE L'ERMITA DE LA MARE DE DÉU DEL SAGAR, (terme municipal d'Herbers, comarca dels Ports). (Full 520).}

Des de la parada anterior cal fer un breu recorregut fins a la sortida del poble d'Herbers, on farem la present aturada, després de recórrer quasi $1 \mathrm{Km}$ des de les immediacions del Molí del Baró. Tot i així, el millor indret per fer l'aturada és a menys de 0 '5 Km del poble, agafant el camí que es dirigeix cap a l'Ermita de la Mare de Deu del Sagar, a llevant del poble.

En conjunt, en bona part d'aquest recorregut, s'han anat tallant els materials cretàcics, eminentment de caràcter calcari. I des d'aquest indret, es pot gaudir d'una bona observació de Sinclinal de l'ermita de la Mare de Deu del Sagar. Aquest, es troba dibuixat entre els afloraments dels materials del Cretaci.

També, i mirant cap al SE, es veu un plec tombat, entre els afloraments dels materials del Cretaci. Per altra banda, en aquest indret on ens trobem ara situats pot veure's com el barranc que baixa de l'ermita de la Mare de Deu del Sagar, ha aprofitat l'artesa del sinclinal per a descriure el seu curs.

Precisament, en aquest indret es pot veure com en travessar una capa de calcàries ha donat lloc a una petita cascada i a un gorg, de gran bellesa. També, des d'aquest lloc, es pot veure una interessant plana d'origen kàrstic. FOTOGRAFIA 4. 
PARADA 7. CARRETERA DES D'HERBERS AL PORT DE TORRE MIRÓ, IMMEDIACIONS DE LES TALLADES, (terme municipal d'Herbers, comarca dels Ports). (Full 520).

Després de fer la parada anterior, cal continuar per la carretera que condueix cap al port de Torre Miró. En arribar a les immediacions del paratge de les Tallades, cal fer la present aturada, després de recórrer uns $2 \mathrm{Km}$ més, des de la parada anterior.

En aquest recorregut hem continuat trobant afloraments dels materials mesozoics, (que per aquests indrets són fonamentalment del Cretaci), els quals formen part de la Serralada Ibèrica, prop de la seva Zona d'Enllaç.

Aquests materials mesozoics es troben força replegats. Així, des d'aquest indret, i mirant cap a ponent es pot veure un bon exemple de sinclinal.

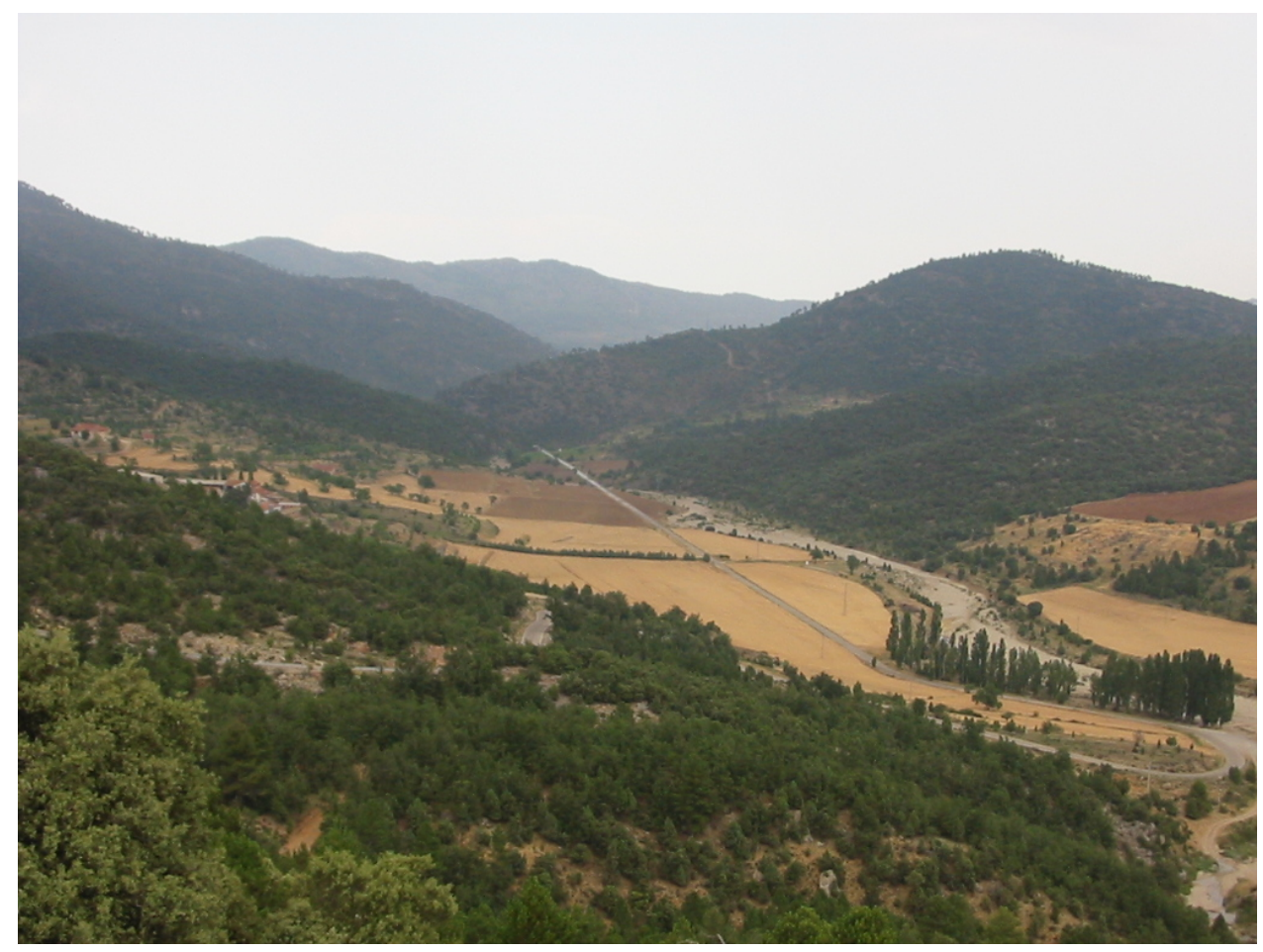

FOTOGRAFIA 4. PARADA 7

Un aspecte de la superfície kàrstica del Sud d'Herbers

PARADA 8- CONDICIONAL. MINETA DEL BARRANC D’ENFERRÉ, (terme municipal d'Herbers, comarca dels Ports). (full 520). 
Des de la parada anterior cal fer un petit recorregut a peu, de menys de 0’3 Km, per tal d'arribar a una petita mineta de carbó, situada al Barranc d'Enferré, per on farem la present aturada.

En aquest breu recorregut, inicialment hem continuat trobant els materials esmentats a les parades anteriors. Tot i així, ben aviat hem començat a trobar afloraments dels nivells cretàcics de la Formació Utrillas. Aquests afloraments es troben constituïts per trams sorrencs i caolinífers, amb nivellets lignitífers.

Precisament, en aquest lloc va haver-hi una mineta, a través de la qual es volien aprofitar aquests nivellets de carbó, els quals són poc importants. Per altra banda són molt ferruginosos, amb presència de PIRITA primària, oxidada a GOETHITA (limonítica) i a MELANTERITA. Tanmateix hi ha presència de CALCITA i de GUIX.

PARADA 9. CARRETERA DES D'HERBERS AL PORT DE TORRE MIRÓ, DAVANT DE LA RABASSA, (terme municipal d'Herbers, comarca dels Ports). (Full 520).

Després de fer la parada anterior, cal continuar per la carretera que condueix cap al port de Torre Miró. En arribar al paratge de la Rabassa, cal fer la present aturada, després de recórrer uns $4 \mathrm{Km}$ més, des de la parada anterior.

En aquest recorregut hem continuat trobant afloraments dels materials mesozoics, (fonamentalment del Cretaci), els quals formen part de la Serralada Ibèrica, prop de la seva Zona d'Enllaç. Així es fan força paleses les estructures, amb clara vergència ibèrica, ESE-ONO i SE-NO.

Així, des d'aquest indret, i mirant cap a la Rabassa, situada a l'altre cantó del Barranc d'Escalona, es poden veure unes interessants estructures, amb una falla entre els materials cretàcics.

Per altra banda, des d'aquest indret, mirant cap al NNE es pot tornar a veure el Sinclinal de la Mare de Deu del Sagar, del qual ja n’hem parlat prop d’Herbers.

Per d'altra banda, des d'aquest indret, mirant cap a Herbers (cap al Nord), es poden veure les dolines i l'interessant poljé. Aquest es troba poc després de sobrepassar la parada anterior, tot just abans de començar a pujar cap a l'indret de la present aturada.

1 PARADA 10. BOLINXA, CARRETERA LOCAL DE TORRE MIRÓ A CASTELL DE CABRES, (Herbeset, terme municipal de Morella, comarca dels Ports). (Full 520)

Després de fer l'aturada anterior, cal continuar cap al S per la carretera N-232. Per ella, en arribar a les immediacions del Port Nou de Torre Miró, caldrà agafar la 
carretera antiga que es dirigeix cap al Port Vell de Torre Miró, d'on eix una carretera que surt cap a llevant.

Per aquesta carretera s'arribarà aviat a l'indret d'on surt (per l'esquerra) la carretera que baixa cap a Herbers. Cal continuar cap a llevant, per tal de fer una nova aturada prop de la cruïlla on eix la carretera que se'n va cap a Herbeset. A l'indret de l'aturada estarem situats prop d'aquest poble, veient-lo sota nostre.

En aquest recorregut, des de l'aturada anterior, hem continuat trobant els materials (eminentment carbonàtitcs), els quals pertanyen al Mesozoic, en especial al Cretaci. Aquests són també els materials que apareixen a l’indret de la present aturada.

Des de l'indret de l'aturada, mirat cap al ENE, es possible de veure amb tota la seva amplitud el Sinclinal de la Mare de Deu del Sagar. FOTOGRAFIA 5.

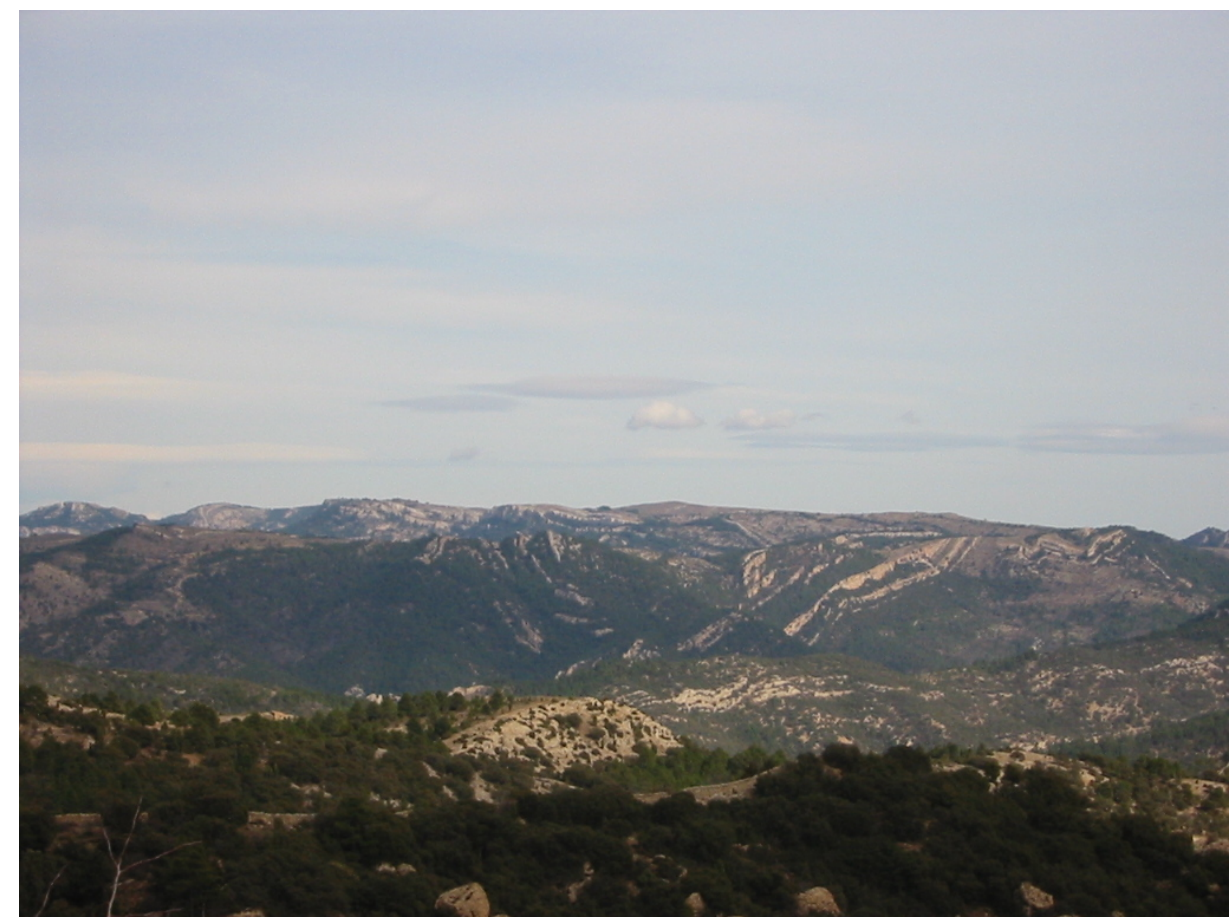

FOTOGRAFIA 5. PARADA 10

El Sinclinal de la de la Mare de Deu del Sagar des de Bolinxa

\section{EN AQUEST INDRET FINALITZA EL RECORREGUT DE L'ITINERARI}




\section{REFERÈNCIES BIBLIOGRÀFIQUES}

GUIMERÀ, J. et altri (1992).- Geologia (II), Història Natural dels Països Catalans, Vol.2, 547 pag. Enciclopèdia Catalana, S.A. Barcelona.

IGME (1972).- Mapa Geológico de España a escala 1:200.000. Sintesis de la Cartografia existente. Hoja y memória nº 41 (Tortosa). Inst. Geol. Min. España. Minist. Indústria. Madrid.

IGME (1974).- Mapa Metalogenético de España a escala 1:200.000. Hoja y memória ${ }^{\circ}$. 41 (Tortosa). Inst. Geol. Min. España. Minist. Indústria. Madrid.

IGME (1975).- Mapa de Rocas Industriales de España a escala 1:200.000. Hoja y memória nº 41 (Tortosa). Inst. Geol. Min. España. Minist. Indústria. Madrid.

IGME (1976).- Mapa Geológico de España a escala 1:50.000. Segunda Sèrie. Hoja y memó. no 520 (Pena-roja de Tastavins). Inst. Geol. Min. España. Min. Indús. Madrid.

IGME (1977).- Mapa Geológico de España a escala 1:50.000. Segunda Sèrie. Hoja y memó. n 545 (Morella). Inst. Geol. Min. España. Min. Indús. Madrid.

MATA-PERELLÓ, J.M. (1989).- Una recerca mineralògica per les terres de l'Ebre: del Matarranya al Priorat. But. Col. Ofi, de Doctors i Llicenciats, ${ }^{\circ}{ }^{6}$ 67, 15pag. Barcelona.

MATA-PERELLÓ, J.M. (1991).- Els Minerals de Catalunya. Arxius de la Secció de Ciències, t. XCIII, 442 pag. Institut d’Estudis Catalans. Barcelona.

MATA-PERELLÓ, J.M. (1992).- Inventario Mineralógico de la Tierra Baja - Matarraña, Revista Rodeno, $\mathrm{n}^{\circ}$ 30, 28 pag. Manresa.

MATA-PERELLÓ, J.M. (1994).- Inventàri Mineralògic de la comarca del Matarranya, Terra Endins, n ${ }^{\circ}$ 6, 23 pag. Manresa.

MATA-PERELLÓ, J.M. (1996a).- Itinerari geològico - mineralògic per les comarques de la Terra Alta i del Matarranya: des d'Arnes a Beseit, a Vall-de-roures i a Fondespatla. Inèdit, 9 pàgines. Manresa. 
MATA-PERELLÓ, J.M. (1996b).- Itinerari geològico i mineralògic entre Gandesa, la Font-calda i Vall-de -roures. Inèdit., 12 pàgines. Manresa.

MATA-PERELLÓ. J.M. (1997).- Recerca geològica i mineralògica per les comarques de la Terra Alta i del Matarranya: des de Gandesa a Bot i Horta de Sant Joan, i des de Vallde-roures a Fondespatlla. Inèdit, 17 pàg. Manresa

MATA-PERELLÓ, J.M. (2006a).- Recorregut de recerca geològica i mineralògica per les comarques de la Terra Alta i del Matarranya: des de Gandesa a Vall-de-roures i a Fondespatlla. Inèdit, 13 pag, Manresa

MATA-PERELLÓ, J.M. (2006b).- Recorregut geològic i mineralògic per les comarques de Matarranya i dels Ports: des de Vall-de-roures a Pena-roja de Tastavins i a Bolinxa. Inèdit. 12 pàgines. Manresa

MATA-PERELLÓ, J.M. i MONTANÉ GARCIA , P. (2003).- Ruta de reconeixement geològic i mineralògic de la zona dels Ports de Beseit: des de Vall-deroures a Fredes. Inèdit. 12 pag. Manresa

RIBA, O. et altri (1976).- Geografia Física dels Països Catalans, Edit. Ketres, 254 pàgines. Barcelona. 